\title{
ATLAS LINGUÍSTICO DA PARAÍBA
}

\author{
PARAÍBA'S LINGUISTIC ATLAS
}

Maria do Socorro Silva de Aragão

\section{Resumo:}

Considerando um levantamento de léxicos realizado em textos de jornais, em crônicas, contos populares, literatura de cordel etc, esse trabalho analisa a língua falada por pessoas de nível cultural mais elevado e a língua regional escrita, tendo resultado na confecção do Atlas Linguístico da Paraíba (ALPB), publicado em dois volumes, em 1984.

Palavras chave: Dialetologia; Lexicologia; Falar paraibano.

\section{Abstract:}

Considering a survey of lexicons carried out in newspaper texts, chronicles, folk tales, string literature, etc. This work analyzes the language spoken by people of a higher cultural level and the regional written language, resulting in the production of the Paraíba Linguistic Atlas (ALPB), published in two volumes, in 1984.

Keywords: Dialectology; Lexicology; Paraíba language.

\section{Introdução}

As facilidades advindas da modernização dos meios de comunicação de massa trazem consigo a tendência de nivelar, em todos os sentidos - espacial, temporal e social -, os vários dialetos ou falares de uma mesma língua. Daí a importância e a necessidade de se estudar, analisar e caracterizar tais falares, antes que sejam absorvidos e desapareçam sem que deles se faça um estudo científico sistematizado e um registro para a história da língua.

Considerando alguns problemas relativos aos estudos dos falares regionais no Brasil, particularmente no Nordeste, os prejuízos que isso vem causando ao conhecimento da realidade linguística regional e nacional e o consequente reflexo negativo no ensino da língua portuguesa em nosso país, é que resolvemos, a exemplo da Bahia e Minas Gerais, inicialmente, e posteriormente, Sergipe e Paraná, realizar a pesquisa para a elaboração do Atlas Linguístico da Paraíba-ALPB.

Vol. 25 - Ano $44-n^{\circ} 1-2020$ 
O Atlas Linguístico da Paraíba faz parte de um projeto de pesquisa mais amplo, o do "Levantamento Paradigmo-Sintagmático do Léxico Paraibano", que compreende, ainda, a análise da língua falada por pessoas de nível cultural mais alto e a linguagem regional escrita, através da análise de jornais, crônicas, contos populares, literatura de cordel e romances de temática regional nordestina, para que se tenha uma descrição, a mais completa possível, do português falado e escrito na região paraibana.

O projeto inicial foi elaborado em 1974. Com a criação do Curso de Pós-Graduação em Letras da UFPB, em 1975, e a necessidade de fixação de suas principais linhas de pesquisa, os estudos dialetológicos foram considerados prioritários e, em conseqüência, o Atlas Linguístico da Paraíba foi um dos projetos escolhidos para ser executado de imediato.

Em 1976 teve início a formação da equipe de pesquisa e o levantamento bibliográfico do material básico a ser consultado.

No final de 1976 iniciou-se a formação técnica dos pesquisadores com a realização, por alguns deles, de cursos na França e Espanha sobre dialetologia e geografia linguística, para uma base teórica mais completa, bem como para uma pesquisa bibliográfica naqueles países de grande tradição nos estudos dialetológicos.

Em 1978 o projeto de pesquisa foi aprovado pela Finep, tendo seu início efetivo e sistemático ocorrido em janeiro de 1979.

Muitos foram os problemas e obstáculos encontrados, desde os técnicos aos administrativos, porém, todos eles superados com esforço e boa vontade por parte dos pesquisadores.

O Atlas Linguístico da Paraíba terá três volumes, dois dos quais já publicados e o terceiro com o material coletado aguardando condições de elaboração.

\section{Caracterização do Atlas Linguístico da Paraíba}

Para a realização da pesquisa e elaboração do Atlas Linguístico da Paraíba, todo um trabalho preliminar de preparação foi feito a fim de se evitar o quanto possível as soluções de urgência e as improvisações.

\subsection{Pesquisa Bibliográfica}

A primeira tarefa foi uma exaustiva pesquisa bibliográfica sobre o que havia sido feito em outros países, no Brasil e no Nordeste, relativamente aos estudos e pesquisas dialetológicas, as várias linhas de pesquisa existentes e os pressupostos teóricos embasadores dos estudos de Dialetologia e Geografia Linguística.

A fim de que os integrantes da pesquisa pudessem estudar e conhecer a bibliografia básica, necessária à correta compreensão e execução do trabalho, foram realizados 
seminários semanais, nos quais cada grupo de dois pesquisadores apresentava aos demais, para discussão, duas obras que haviam lido, comentado e resumido.

Foram consultados, no país e no exterior, cerca de 24 Atlas Linguísticos de vários países, bem como obras gerais de Dialetologia, Geografia Linguística, Sociolinguística e Linguística Geral.

\subsection{Escolha das Localidades}

Foram escolhidos 25 municípios como base e mais três satélites para cada base, num total de 100 municípios, cobrindo todo o Estado.

São municípios bases João Pessoa, Mamanguape, Belém, Guarabira, Itabaiana, Esperança, Campina Grande, Umbuzeiro, Barra de Santa Rosa, Picuí, Soledade, Cabaceiras, Taperoá, Serra Branca, Congo, Monteiro, Patos, Catingueira, Catolé do Rocha, Pombal, Princesa Isabel, Sousa, Itaporanga, Cajazeiras e Conceição.

Os municípios-satélites serviram para controle e convalidação dos dados obtidos nos municípios base, não aparecendo, portanto, nas Cartas.

Efetuou-se, a seguir, junto à Fundação Instituto Brasileiro de Geografia e Estatística - IBGE, um levantamento de dados geográficos e sócio-econômico-culturais de todos os municípios a serem pesquisados, de interesse para o trabalho, o qual constou de: nome do município; etimologia do nome do município; microrregião paraibana onde se localiza; limites; adjetivo gentílico; distritos; distância da capital; histórico do município; aspectos físicos (latitude, longitude, altitude, área), aspectos demográficos (população do município e da sede, densidade demográfica); aspectos econômicos (principais atividades econômicas, estabelecimentos rurais e industriais, hotéis, restaurantes, hospitais); aspectos sócio-culturais (profissionais em exercício, escolas de $1^{\circ}$ e $2^{\circ}$ graus, superiores, associações culturais, bibliotecas, cinemas, jornais, rádios, canais de TV que sintonizam); meios de transporte e vias de acesso; intercâmbio comercial e cultural além de outras informações.

\subsection{Escolha dos Informantes}

A escolha dos informantes obedeceu aos seguintes critérios: ter nascido na localidade ou no município; pertencer à faixa etária entre 30 e 75 anos; ter nível de instrução variando entre analfabeto e primário completo; não ter saído da localidade por mais de um ano; ser filho de pais nascidos na região; possuir boas condições de saúde e de fonação; homens e mulheres; profissões variadas, por ser o questionário geral; trabalhar naquela produção específica, no caso do questionário específico.

Em cada município foram entrevistados um mínimo de três e um máximo de dez informantes, assegurando-se assim uma amostragem representativa do seu falar.

Vol. 25 - Ano $44-n^{\circ} 1-2020$ 


\section{$1.4 O$ Questionário}

A versão do questionário aplicado, que foi publicado, em 1980, pela Editora da $\mathrm{UFPb}$ é o resultado do aperfeiçoamento de três outras versões testadas e reformuladas sucessivamente em seis municípios, com 12 informantes diferentes.

O questionário foi dividido em duas partes: uma geral, com 289 questões e uma específica, com 588 questões. A geral, compreendendo os seguintes campos semânticos: a terra, o homem, a família, habitação e utensílios domésticos, aves e animais, plantação, atividades sociais.

A parte específica diz respeito aos cinco principais produtos agrícolas da Paraíba: mandioca, cana-de-açúcar, agave, algodão e abacaxi.

Apesquisa foi direta, in loco, utilizando-se conversação dirigida através do questionário.

Para a elaboração do questionário específico da cana-de-açúcar e da mandioca foram utilizadas algumas questões de outros questionários, como os dos professores Alzir Oliveira, Otília Idalina Maia de Vasconcelos e Yara Lyra de Macedo, da UFPB.

\subsection{As Entrevistas}

Para a aplicação do questionário, nos municípios, foram feitos contatos com as Prefeituras Municipais, Secretarias da Educação, de Assistência Social, Movimento Brasileiro de Alfabetização - Mobral, Empresa de Assistência Técnica e Extensão Rural - Emater, Centros Sociais Urbanos, Cooperativas e Associações de Classe, que serviram de intermediários para as primeiras abordagens e apresentações junto aos informantes.

As entrevistas foram as mais informais possíveis, havendo toda uma conversação preliminar em que se procurava deixar o informante descontraído e à vontade para responder às questões. Para facilitar a compreensão das questões usaram-se desenhos esquemáticos e pequenos objetos que eram mostrados aos informantes. As questões eram formuladas de modo simples enquanto se mostrava o objeto ou imitava-se a ação.

As entrevistas foram realizadas nas residências dos informantes, no ambiente de trabalho ou ainda em locais como a Prefeitura, o Centro Social Urbano, Cooperativas ou Associações.

Se a escolha dos locais trouxe alguns problemas de ruídos nas gravações, por outro lado ganhou-se bastante na espontaneidade e informalidade de que se revestiram por estar o informante em seu meio ambiente.

Para a gravação das entrevistas usou-se gravadores portáveis marca Crown, National, Sanyo e Panasonic, com boa capacidade de resposta e fitas cassetes marcas TDK-SA e BASF, de ferrite e dióxido de cromo, C/60. 
As entrevistas gravadas no campo em fita cassete e com gravadores portáteis foram reproduzidas para fitas de rolo, marca SCOTCH e BASF, de dióxido de cromo, com 1.200 e 1.800 pés, utilizando-se um gravador master AKAY 4000 IDB, com eliminador de ruídos, no Laboratório de Fonética da UFPb.

$\mathrm{Na}$ audição e transcrição das fitas usou-se head-phones estéreos marca Selenium, amplificador de som QUASAR QA 5500 e caixas acústicas QC 500.

Para o registro de fatos étnicos e sociais importantes para a pesquisa utilizou-se uma máquina fotográfica Yashica ME 1, com flash e uma máquina filmadora Minolta, sonora SL 660.

\subsection{As Transcrições Fonéticas}

Para a transcrição fonética das entrevistas utilizou-se o Alfabeto Fonético Internacional, com um número reduzido de sinais e diacríticos a fim de facilitar a leitura do trabalho.

A transcrição é ampla e geral, por ser auditiva e ter sido levada a efeito sem o uso de instrumentos de fonética experimental ou sofisticações técnicas, o que não diminui o seu valor, face aos cuidados com que foi feita. Todas as fitas foram ouvidas por mais de um pesquisador, que testavam e discutiam entre si a transcrição feita.

\subsection{Seleção do Material para as Cartas}

Para a seleção dos vocábulos temas das Cartas foram utilizados vários critérios, entre eles, a representatividade do vocábulo para o falar regional, a riqueza da variação léxica e fonética do vocábulo e a possibilidade de comparação com outros Atlas Linguísticos do Brasil.

Selecionados os vocábulos, foram feitas fichas individuais de cada um deles, relativas a cada informante.

Face ao volume do material que se enquadrava nos três principais critérios, realizou-se uma nova seleção em que predominou o critério da riqueza da variação léxica e fonética dos vocábulos. Estes vocábulos passaram a constituir os temas de cada uma das cartas léxicas e fonéticas do Atlas.

\subsection{Apresentação das Cartas}

O Atlas Linguístico da Paraíba é iniciado com o mapa da Paraíba e sua localização no Brasil, as microrregiões homogêneas, a divisão municipal, as localidades, os gentílicos dos habitantes das localidades, os inquiridores e os informantes. Para a confecção das Cartas foram usados mapas em escala de 1/2.000.000 e, apenas na divisão municipal, mapa em escala de 1/1.500.000 A seguir, vêm as Cartas propriamente ditas. 
Para a elaboração das Cartas utilizou-se apenas as 68 questões que apresentaram alta frequência de ocorrência e maior número de variantes léxicas e fonéticas.

A numeração das localidades nas Cartas foi feita na ordem leste-oeste e norte-sul.

O Atlas é composto de Cartas Léxicas e Cartas Fonéticas, intercaladas. Assim, por exemplo, a Carta Léxica $\mathrm{n}^{\mathrm{0}} 030$ da pergunta 29, arco-íris, é seguida pelas Cartas Fonéticas $\mathrm{N}^{\mathrm{s}} \mathrm{s}$ 031, 032, 033, correspondentes às variantes fonéticas de arco-íris, arcoceleste e olho-de-boi.

As Cartas são compostas do seguinte modo:

— parte superior: título

- da esquerda para a direita:

— número da carta

— vocábulo

— nas Cartas Léxicas, o número da pergunta no questionário

— as Cartas Fonéticas não trazem o número da pergunta por ser o mesmo da Carta Léxica correspondente.

- na parte extrema direita, ao lado do mapa, as convenções utilizadas: círculos, quadrados e triângulos vazios, cheios e parcialmente cheios.

As Cartas estão divididas por campos semânticos do seguinte modo:

- a terra: cartas 001 a 043

- o homem: cartas 044 a 090

- a família: cartas 091 a 107

- habitação e utensílios domésticos: cartas 108 a 113

- aves e animais: cartas 114 a 129

- plantação: cartas 130 a 137

- atividades sociais: cartas 138 a 149.

A ordem das Cartas segue a ordem das perguntas no questionário.

\section{Análise do material coletado}

O material colhido para a elaboração do Atlas Linguístico da Paraíba, por sua riqueza em quantidade e qualidade, permite análises diversas, do nível fonético-fonológico ao semântico; do léxico ao morfossintático.

Na elaboração dos dois primeiros volumes do Atlas foram feitas algumas análises fonético-fonológicas e morfossintáticas, que têm sido complementadas e enriquecidas com trabalhos monográficos, dissertações, artigos, conferências e comunicações em eventos nacionais e internacionais. 


\subsection{Análise Fonético-Fonológica}

\subsubsection{Quadro dos Fonemas}

A partir das análises fonético-fonológicas do material coletado foram estabelecidos os quadros dos fonemas vocálicos, consonantais e semivocálicos; as variantes, livres e combinatórias e os arquifonemas.

\subsubsection{Posição dos Fonemas nos Signos}

Todos os fonemas da língua portuguesa ocorreram no falar da Paraíba, porém sua posição nos signos apresenta certas marcas do falar regional paraibano, uma vez que em determinadas posições os fonemas se neutralizam surgindo daí os arquifonemas, que têm uma ocorrência bastante alta. Excetuando-se as variantes combinatórias dos fonemas vocálicos $/ a /, / e /, / i / / o /, / u /$, todas as demais variantes do falar paraibano são variantes dos arquifonemas e não dos fonemas.

\subsubsection{Possibilidades Combinatórias dos Fonemas}

No que se refere às possibilidades combinatórias dos fonemas formando os ditongos, tritongos e grupos consonantais, no falar paraibano surgem ditongos puramente fonéticos, onde, normalmente eles não deveriam ocorrer, ou seja, na articulação foi acrescentada, sempre em sílabas tônicas finais, uma semivogal, criando, assim, um novo tipo de ditongo. Por outro lado, alguns ditongos normais na língua portuguesa, desaparecem no falar paraibano, graças ao fenômeno da monotongação.

\subsubsection{Outros Fenômenos Observados}

Outros fenômenos bastante frequentes no falar paraibano são a queda dos fonemas $/ l /, / R / e / s /$ em posição final absoluta; a iotização do / $\varnothing /, /$ ' / $e / R /$; a redução do grupo / nd /; a queda do grupo / ad / e a semivocalização do fonema / l /

Em trabalhos mais específicos a partir do material do Atlas pode-se, também, fazer uma série de observações quanto ao comportamento dos fonemas pretônicos em seu abaixamento ou elevação, chegando-se à conclusão de que os contextos subsequentes são importantes, porém os contextos sociais não são elementos essenciais para a definição dessas realizações; há uma predominância das vogais médias abertas, anterior [ $E$ ] e posterior [ ]; no caso da elevação, a passagem se dá diretamente do [ $E$ ] para o [ $i$ ] e do [ ] para o [ $u$ ]; a elevação existe, porém com frequência mínima; as nasais na sílaba subsequente favorecem a elevação.

No que diz respeito à despalatalização e iotização do / '/ e / ø /, são de grande importância os contextos sócio-educativo-culturais, nos informantes analfabetos ou alfabetizados, de baixa renda econômica, bem como os de faixas etárias mais altas, de 61 a mais de 70 anos, uma vez que esses informantes fazem sistematicamente - podendo-se 
falar numa norma - a despalatalização seguida da iotização, ou seja: / $/>/ l+j /$, e / ø $/>/ n+j /$.

\subsection{Análise Léxica do Material}

Para a análise léxica do corpus foram considerados os seguintes aspectos:

a) a frequência e distribuição das variantes em todo o estado e em cada ponto de per si;

b) a estruturação das variantes em formas de lexias simples, compostas, complexas e como expressões completas;

c) o uso de formas diminutivas com valor afetivo ou representativo;

d) o uso de adjetivos qualificativos em lexias compostas e complexas;

e) o número de variantes lexicais de cada Carta temática.

Após a análise de algumas das cartas léxicas, chegamos às seguintes conclusões:

a) os temas analisados apresentam uma grande variação lexical;

b) as variantes distribuem-se em toda a região de forma bastante irregular e dispersa, o que impede sejam traçadas isoléxicas de áreas definidas em cada uma das subregiões abrangidas pelo Atlas;

c) a riqueza lexical encontrada na Paraíba e a dificuldade de se determinar suas áreas lexicais indicam uma grande uniformidade e interpenetração das sub-regiões, inclusive com a disseminação de inovações e criações lexicais;

d) muitas das variantes coexistem em um mesmo informante, em uma mesma subregião e num mesmo ponto, não sendo, portanto, exclusivas, o que mostra a uniformidade na distribuição geográfica daquela forma para o mesmo conceito;

e) um mesmo informante pode conhecer mais de uma forma, embora quando perguntado diga em primeira mão a forma mais consagrada pela região ou pelo Estado, complementando-a, a seguir, com outras formas de seu conhecimento;

f) as variantes lexicais analisadas possuem várias estruturas que podem ser lexias simples, compostas, complexas e expressões completas;

g) coexistem no Estado tipos lexicais os mais variados, representativos de faixas etárias e níveis socioculturais diferentes, resultantes de influências sociais, econômicas, culturais e linguísticas tanto regionais como de âmbito nacional.

\subsection{Análise Morfossintática}

A partir de algumas análises morfossintáticas do material coletado podemos fazer algumas observações: 


\subsubsection{Quanto ao Nome}

\subsubsection{Gênero}

a) $\mathrm{Na}$ indicação, quer do masculino, quer do feminino, há a tendência para a substituição da forma "e" $[i]$ por "a" $[a]$ e "o" $[u]$, como nos exemplos: "monte" > "monto" [ 'mõtu ] "tempestade" > "tempestada" [te)pES'tada ]

A ocorrência do fato acima referido, parece-nos indicar, na língua falada da região paraibana, uma tendência de uniformização, por analogia, das terminações "o" para o masculino e "a" para o feminino.

b) Fenômeno inverso ocorre quando se substitui as formas "o" do masculino e "a" do feminino, por uma forma única "e" $[i]$, como nos exemplos: “presépio"> "presépe" [ $p R E ' z E p i]$ "mestra"> "mestre" [ 'mES tRi]

\subsubsection{Número}

a) Há uma tendência para a eliminação das marcas redundantes de plural, sendo o número indicado apenas pelo determinante, quer no substantivo, quer no adjetivo:

"as barreiras" > "as barreira" [ 'ajs ba'úeRa ]

b) Não é realizada a pluralização dos nomes em "-ão":

“os pães” > “os pão” ['ujs 'pãw]

c) a palavra "povo" leva sempre o verbo para o plural:

"O povo vai todo para a casa dele" > "O povo vão tudo para a casa dele"

d) Supressão de "s" das palavras Jesus e Judas, uma vez que para as pessoas do povo o "s" é sempre marca de plural:

"o Judas" > “o Juda", "Jesus" > "Jesui".

\subsubsection{Grau}

a) O gramema diminutivo "-inho" freqüentemente é reduzido para "-im": "pauzinho"> "pauzim" [paw'zi) ]

b) Há uma tendência generalizada do uso do diminutivo, não por tamanho mas por afetividade:

“rapaizinho"> rapaizim" [rapaj'zi) ] 
Muito outros fatos morfossintáticos têm sido analisados, quanto ao verbo, por exemplo, mas por não haver tempo suficiente vamos deixar de comentá-los

\section{Considerações Finais}

O presente trabalho teve como objetivo uma rápida caracterização do Atlas Linguístico da Paraíba, através da metodologia utilizada para sua elaboração e de uma análise um tanto superficial dos principais fatos fonético-fonológicos, léxicos e morfossintáticos por ele registrados.

De acordo com o que dissemos anteriormente, a riqueza do material coletado poderá ser explorada e trabalhada durante muito tempo, até que se possa ter uma caracterização e descrição completa do falar paraibano, permitindo sua utilização por pesquisadores e professores que trabalham com a Língua Portuguesa em nosso país.

\section{Referências}

AGUILlerA, Vanderci de A. Atlas Linguístico do Paraná. Londrina: Universidade Estadual de Londrina, 1993.

ARAGÃO, Maria do Socorro Silva de e BEZERRA DE MENEZES, Cleusa P. Atlas Linguístico da Paraíba. Brasília: UFPB/CNPq, Coordenação Editorial, 1984, v. 1, 2.

ARAGÃO, Maria do Socorro Silva de. Aspectos léxicos do atlas Linguístico da Paraíba. Estudos Linguísticos e Literários,n. 5, p. 129-150. Salvador: UFBA, 1986.

ARAGÃO, Maria do Socorro Silva de. A despalatalização e iotização no atlas Linguístico da Paraíba. II ENCONTRO NACIONAL DE FONÉTICA E FONOLOGIA. Niterói: UFF, 1992.

ARAGÃO, Maria do Socorro Silva de. Aspectos fonéticos do atlas Linguístico da Paraíba - As vogais pretônicas. IX ENCONTRO NACIONAL DA ANPOLL.Anais.João Pessoa: ANPOLL, 1995, v.2, Tomo I, p. 833-840.

BRANDÃO, Sílvia de F. A geografia linguística no Brasil. São Paulo: Ática, 1991.

FERREIRA, Carlota et al. Atlas Linguístico de Sergipe. Salvador: UFBA - Instituto de Letras/Fundação Estadual de Cultura de Sergipe, 1987.

FERREIRA, Carlota. Diversidade do português do Brasil- estudos de dialetologia rural e outros. Salvador: UFBA, 1994. 
NASCENTES, Antenor. Bases para a elaboração de atlas Linguístico do Brasil. Rio de Janeiro: Casa de Rui Barbosa, 1958.

NASCENTES, Antenor. O idio ma nacional. Rio de Janeiro: Livraria Acadêmica, 1960.

ROSSI, N. Atlas prévio dos falares bahianos. Rio de Janeiro: INL, 1963.

SILVA NETO, Serafim. Guia para estudos dialetológicos. Florianópolis: s. ed., 1955.

ZÁGARI, Mário Roberto L. et al. Esboço de um atlas Linguístico de Minas Gerais. Rio de Janeiro: Fundação Casa de Rui Barbosa, 1977.

Vol. 25 - Ano $44-n^{\circ} 1-2020$ 